\title{
THREE-DIMENSIONAL EVALUATION OF THE OROPHARYNGEAL AIRWAY CHANGES AFTER BIMAXILLARY ORTHOGNATHIC SURGERY USING CONE-BEAM COMPUTER TOMOGRAPHY: A RETROSPECTIVE ANALYSIS
}

\author{
Mohamed Farid Shehab*, Nermeen H. Sorour* and Ghada Abdel Monim***
}

\begin{abstract}
Objectives: The purpose of this study was to assess and compare the volumetric, cross sectional surface area, and linear changes of the oropharyngeal airway in patients following bimaxillary orthognathic surgery using 3-D cone beam computer tomography (CBCT) imaging.

Material and Methods: A total thirty patients have been included in the study. Fifteen patients underwent maxillary and mandibular advancements (Group A), while the other fifteen patients underwent maxillary advancement and mandibular setback (Group B). Volume changes in airways, surface area, and linear values from specified hard and soft tissue parameters have been reported.

Results: Statistical analysis comparing the results of the two groups showed that Group A was statistically significantly higher mean \% increase than Group B in volumetric, surface area and linear measurements. Both groups failed to show a statistically significant change in surface area post-operatively. Group B showed no statistically significant change in linear measurements at any levels.
\end{abstract}

Conclusion: Significant changes in the measured parameters was observed in patients performing maxillary and mandibular advancement thus increasing the airway volume; which can provide surgeons with a greater confidence that this combination movement is not altering the airway in a negative way.

KEY WORDS: Orthognathic surgery, bimaxillary surgery, 3D volumetric airway changes, Cone-beam CT, Oropharyngeal airway changes.

Associate Professor, Oral and Maxillofacial Surgery Department, Faculty of Dentistry, Cairo University, Cairo, Egypt.

** Lecturer, Oral and Maxillofacial Surgery Department, Faculty of Dentistry, Cairo University, Cairo, Egypt. 


\section{INTRODUCTION}

Bimaxillary orthognathic surgery or corrective jaw surgery is designed to correct and improve facial dysmorphology, skeletal disharmony of the jaws and its related structures, growth discrepancies, sleep apneas, and problems of malocclusion with associated orthodontic problems. In addition to its beneficial effects, it has been widely used to optimize soft tissue outcomes. ${ }^{(1)}$ Several studies have argued that following surgery, either single jaw or double jaw surgery, changes in the tongue position , the hyoid bone and the pharyngeal wall have occurred as a result of changes in muscle and ligament attachments to the bone, resulting in changes in airway space. Previous studies were limited in quantifying the volume and position of changes in the airway before and after surgery. Few studies have attempted to look at volumetric, surface area and linear changes in the same patient. ${ }^{(2-4)}$

Lateral cephalography, has been used as 2-dimensional (2D) technology to assess airways following orthognathic surgery due to its simplicity, availability and low cost; however, it may be inconvenient for assessment of the airway since it has just limited to two-dimensional imaging of complicated 3-dimensional (3D) anatomical structures and might overlook much of the anatomical information required for proper evaluation. ${ }^{(5,6)}$ Recently, computed tomography (CT) and magnetic resonance imaging (MRI) techniques have been introduced for airway evaluation after orthognathic surgeries due to their ability to represent the airway's real 3Dmorphology; however, their use is limited by high level of irradiation, cost, and restricted accessibility ${ }^{(6,7)}$ Cone-beam computed tomography (CBCT) has been improved since its introduction of in 1998, with decreased radiation exposure and costs relative to conventional CT, and can be used for both orthodontic and surgical diagnosis as well as for treatment planning. ${ }^{(8,9)}$
Recent studies have emphasized the use of (3D) scans for pharyngeal airway investigations as it allow visualization of the internal structures by eliminating the external structures, maintaining the more precise representation of anatomical feature. In addition, this method allows measuring linear distances, the area, and the volume of the airway. ${ }^{(2,9-12)}$ the effects of orthognathic surgeries on the airway have been studied by several authors. ${ }^{(13-17)}$ many have attempted to determine the impact of bimaxillary progression or single mandibular advancement on various upper airway compartments. ${ }^{(1,4,12)}$ Some have evaluated the improvement in overall volume in response to single-jaw or bimaxillary progression surgery. ${ }^{(14-16)}$ Several studies in the literature have reported the airway changes after orthognathic surgery however, to our knowledge there was no reports on its effect in Egyptian population.

This study aimed to assess and compare the volumetric, cross sectional surface area, and linear changes of the oropharyngeal airway by using 3-D cone beam computer tomography (CBCT) imaging following two different bimaxillary orthognathic surgeries.

\section{MATERIALS AND METHODS}

The study included thirty patients who were chosen from the orthognathic surgery database files performed at oral and maxillofacial surgery department, Faculty of Dentistry, Cairo University from 2017 to 2019. Patients with previous orthognathic surgeries, craniofacial syndromes, mandibular midline shifts greater than $3 \mathrm{~mm}$, and any other former surgeries in the oral and maxillofacial region including tonsillectomy and adenoidectomy were excluded from the study.

The patients were divided equally into two groups, Group A comprising fifteen patients who underwent maxillary and mandibular advancements, while Group $\boldsymbol{B}$ comprising fifteen patients who underwent maxillary advancement with mandibular 
setback. The maxillary surgery performed included Le Fort I osteotomy extending from the piriform going through the zygomatic buttress till the pterygoid plates while the mandibular surgery included bilateral sagittal split osteotomies (BSSO). Rigid internal fixation of the maxilla and mandible were performed for all patients using miniplates and screws. Patients who had performed pre and postoperative follow up CBCT scans ranging from 3-6 months were collected.

The pre and postoperative CBCT scans were analyzed using a surgical planning software (Mimics ${ }^{\circledR}$ medical 19.0 software, materialise ${ }^{\circledR}$ Interactive Medical Image Control System). The DICOM files were imported into the 3D software and were reconstructed into volumetric (3D reconstruction), sagittal, coronal, and axial slices. The airway space was then segmented using the software tools and the changes in the airway volume, surface area and linear measurements from a predefined hard and soft tissue parameter were recorded on the $2 \mathrm{D}$ and $3 \mathrm{D}$ views. Inter and intra observer reliability was used by recording three independent measurements for each value in order to increase accuracy.

The 3-D volumetric analysis of the airway was defined by two planes; a superior plane constructed at the level of the hard palate (HP), from the anterior nasal spine (ANS), posterior nasal spine (PNS), posterior pharyngeal wall (PP) and an inferior plane constructed at the level of the third cervical vertebrae (3CV) (Fig 1). Then, the airway was segmented three dimensionally (Fig, 2) and the volume was calculated. Superimposion of the pre and postoperative 3D airway was also done (Fig, 3). The 2-D linear measurements included: the minimally constricted surface area at the level of the soft palate (SP) and tongue (Tg) on the axial crosssectional view (Lateral and antero-posterior (A-P) dimensions of the airway) (Fig, 4) and finally, the linear distance change from the genial tubercles to the hyoid bone was measured pre and postoperatively $(\boldsymbol{F i g}, 5)$.

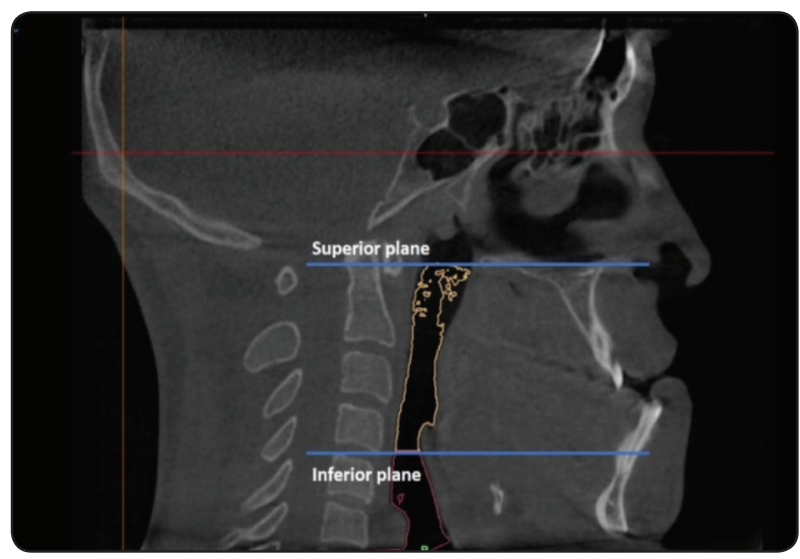

Fig. (1) Showing Superior and Inferior planes defining the airway volumetric boundaries on the sagittal view.

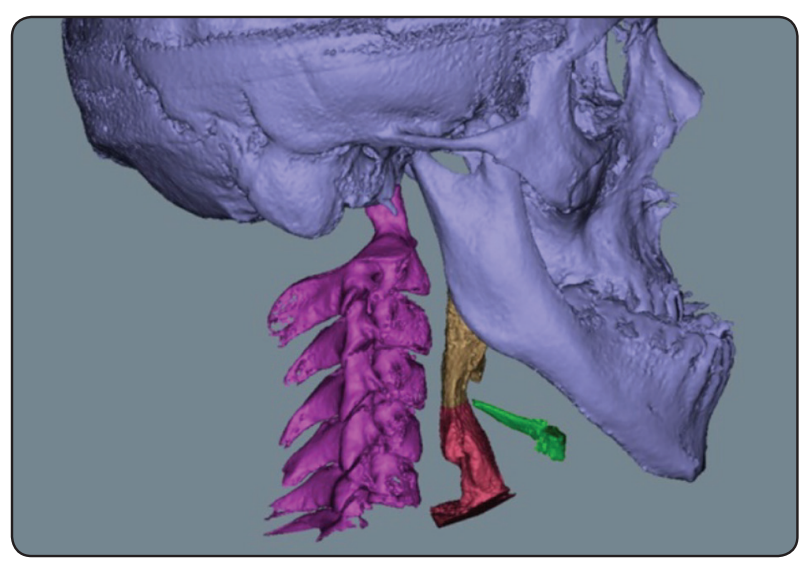

Fig. (2) Showing a 3D view of the segmented airway volume (Orange), cranio-cervical vertebrae (purple), hyoid bone (green) and skull (blue) for pt. No. 5 in Group B.

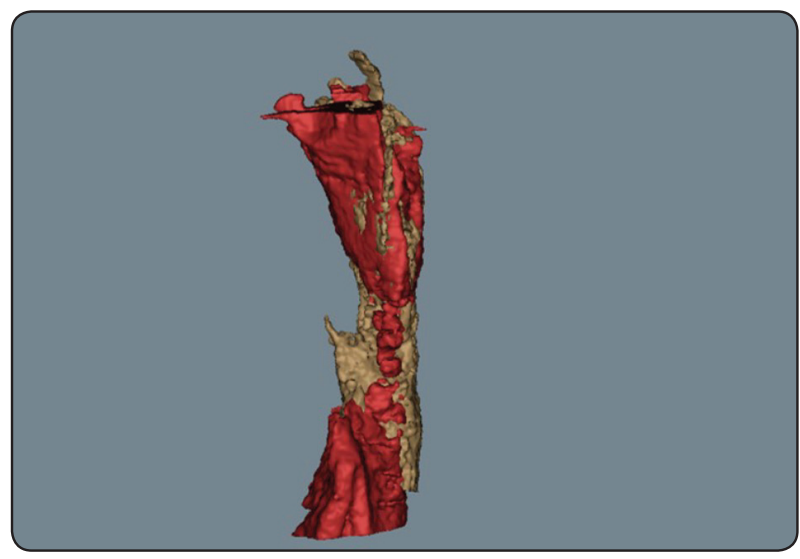

Fig. (3) Showing superimposition of the pre and post-operative segmented Oropharyngeal airway volumes. 


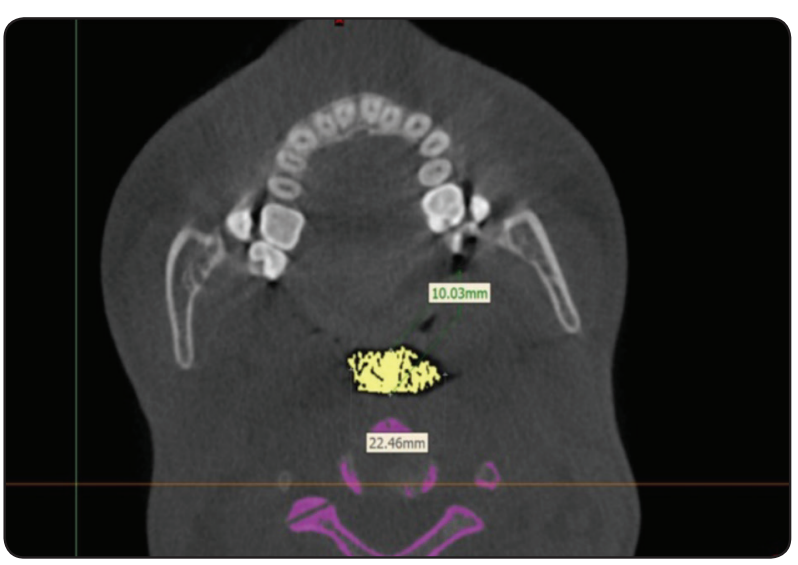

Fig. (4) Showing 2-D linear measurements of the minimally constricted surface area at the level of the soft palate (SP) and tongue (Tg) for pt. No. 5 in Group B on the axial view.

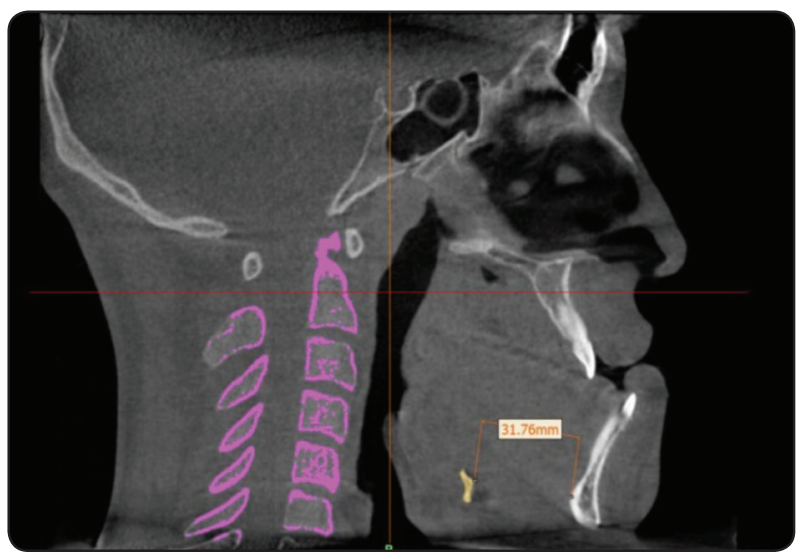

Fig. (5) Showing preoperative linear distance measured for pt. No. 5 in Group B from the genial tubercles to the hyoid bone.

Results were evaluated by calculating percent change of 3-D volumetric, surface area changes and linear measurements by using a paired t-test to explore statistical significance pre and post operatively. Percent change for the groups was averaged for all measurements.

\section{Statistical Analysis}

Numerical data were explored for normality by checking the distribution of data and using tests of normality (Kolmogorov-Smirnov and Shapiro-Wilk tests). All data showed normal (parametric) distribution except for percentage changes in all measurements data which showed non-normal (non-parametric) distribution. Data were presented as mean and standard deviation (SD) values. For parametric data; repeated measures ANOVA test was used to compare between the groups as well as to study the changes by time within each group. Bonferroni's post-hoc test was used for pair-wise comparisons. For non-parametric data, Mann-Whitney U test was used to compare between the two groups. Qualitative data were presented as frequencies and percentages. Fisher's Exact test was used to compare between the two groups. The significance level was set at $\mathrm{P} \leq 0.05$. Statistical analysis was performed with IBM SPSS Statistics for Windows, Version 23.0. Armonk, NY: IBM Corp.

\section{RESULTS}

Thirty patients included in our study, Group A included 9 male (60\%) and 6 (40\%) female with an average age $34.9 \pm 7.5$ while Group B included 8 male $(53.3 \%)$ and 7 female (46.7\%) with an average age $30.4 . \pm 8.6$. There was no statistically significant difference between mean ages values or gender distributions in the two groups. (Table 1)

In both groups the average maxillary advancement was $5.5 \mathbf{~ m m}$ (range of 3-7 mm). In Group A The averaged mandibular advancements $\mathbf{5 . 3} \mathbf{m m}$ (range of $3-10 \mathrm{~mm}$ ) while the average mandibular setback was $\mathbf{3 . 3} \mathbf{~ m m}$ (range 3 - $7 \mathrm{~mm}$ ) In Group B with the postoperative follow up ranging from 90-180 days (average of 152.56 days). 
TABLE (1) Mean, standard deviation (SD), frequencies (n), percentages and results of Student's t-test and Fisher's Exact tests for comparisons of demographic data in the two groups

\begin{tabular}{cccc}
\hline & $\begin{array}{c}\text { Group A } \\
(\mathrm{n}=15)\end{array}$ & $\begin{array}{c}\text { Group B } \\
(\mathrm{n}=15)\end{array}$ & $P$-value \\
\hline Age (Years) & & & \\
Mean (SD) & $34.9(7.5)$ & $30.4(8.6)$ & 0.139 \\
\hline Gender [n (\%)] & & & \\
Male & $9(60 \%)$ & $8(53.3 \%)$ & 0.713 \\
Female & $6(40 \%)$ & $7(46.7 \%)$ & \\
\hline
\end{tabular}

*: Significant at $P \leq 0.05$

\section{Oropharyngeal Airway Volume $\left(\mathrm{mm}^{3}\right)$ (OPV)}

The volumetric changes for the maxillary and mandibular advancement group (Group A) showed statistically significant increase in airway volume postoperatively. The mean starting volume of $\mathbf{1 0 9 8 4}$ $\mathrm{mm}^{3}$ increased to $\mathbf{1 5 5 2 9 . 3} \mathrm{mm}^{3}$. This corresponded to an average increase in $\%$ of change of the airway volume by $46.3 \%$. While in the maxillary advancement and mandibular setback group (Group B) showed no statistically significant change in OP airway volume post-operatively with the mean volume change pre-operative to post-operative was

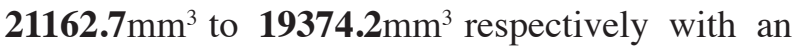
average volumetric decrease of $8.7 \%$. By compering results of two groups revealed that group $\boldsymbol{A}$ showed statistically significantly higher mean $\%$ increase in OP airway volume than group B. (Table 2)

\section{Surface Area measurements $\left(\mathrm{mm}^{2}\right)$}

In Group $\boldsymbol{A}$ The changes in the mean of surface area from pre to post-operative was $\left(\mathbf{5 2 2 9} \mathbf{m m}^{2}\right.$ $5933.5 \mathrm{~mm}^{2}$ respectively) with percentage change $14 \%$, while changes in the mean of surface area from pre to post-operative in Group B was $\left(\mathbf{6 8 0 1 . 1 m ^ { 2 }} \mathbf{m}^{2}\right.$ $6221.1 \mathrm{~mm}^{2}$ respectively ) with an average surface area decrease of $8.7 \%$. Although, there was no statistically significant change in surface area postoperatively in both groups but, the comparison between two groups revealed that Group $\boldsymbol{A}$ was a statistically significantly higher mean $\%$ increase in surface area than Group B .

Regarding to the minimal constricted axial area at the level of the soft palate (SP) and tongue (Tg), Group A showed a statistically significant increase in mean minimal constricted axial area at the soft palate (SP) and tongue ( $\mathrm{Tg}$ ) post-operatively, the mean values increased from 192.3 to $344.6 \mathrm{~mm}^{2}$ with $\%$ change $193 \%$ and from 281.6 to $444.2 \mathrm{~mm}^{2}$ with $\%$ change $122.4 \%$ respectively. However, Group B fails to show significant changes in terms of axial cross-sectional surface area post-operatively at both levels, the soft palate (SP) and tongue (Tg). Comparing the two groups; Group A showed statistically significantly higher mean percentage increase than Group $\boldsymbol{B}$ at the minimal constricted axial area of the SP and the Tg. (Table 2)

\section{Linear measurements (mm)}

Group $\boldsymbol{A}$ showed a statistically significant increase in the mean of linear measurements at all levels post-operatively except in Lateral dimension at Tongue $(\min \mathbf{T})$ there was no statistically significant change. While in Group B there was no statistically significant change in mean of all linear measurements post-operatively. Comparing the two groups; Group A showed statistically significantly higher mean \% increase than group $\boldsymbol{B}$ in all liner measurements except in lateral and A-p dimension measurements at the tongue, the two groups showed no statistically significant difference between mean $\%$ changes.(Table 3 ) 
TABLE (2) Descriptive statistics, results of repeated measures ANOVA test for comparison between 3D volume and surface area measurements in the two groups, changes within each group and MannWhitney $\mathrm{U}$ test for comparison between percentage changes in the two groups

\begin{tabular}{|c|c|c|c|c|c|c|c|}
\hline \multirow{2}{*}{$\begin{array}{l}\text { 3D volume and } \\
\text { surface area } \\
\text { measurements }\end{array}$} & \multirow{2}{*}{ Time } & \multicolumn{2}{|c|}{$\begin{array}{c}\text { Group A } \\
(\mathrm{n}=15)\end{array}$} & \multicolumn{2}{|c|}{$\begin{array}{c}\text { Group B } \\
(\mathrm{n}=15)\end{array}$} & \multirow{2}{*}{$P$-value } & \multirow{2}{*}{ Effect size } \\
\hline & & Mean & SD & Mean & SD & & \\
\hline \multirow{5}{*}{$\begin{array}{l}\text { OP airway } \\
\text { volume }\left(\mathbf{m m}^{3}\right)\end{array}$} & Pre-operative & 10984 & 4450.3 & 21162.7 & 5855.9 & $0.031 *$ & Partial Eta Squared $=0.568$ \\
\hline & Post-operative & 15529.3 & 5099.4 & 19374.2 & 5915.5 & 0.366 & Partial Eta Squared $=0.137$ \\
\hline & Change $\%$ & 46.3 & 16.4 & -8.7 & 2.6 & $0.025^{*}$ & $d=2.582$ \\
\hline & $P$-value & \multicolumn{2}{|c|}{$0.012^{*}$} & \multicolumn{2}{|c|}{0.318} & & \\
\hline & $\begin{array}{l}\text { Effect size } \\
\text { (Partial Eta Squared) }\end{array}$ & \multicolumn{2}{|c|}{0.680} & \multicolumn{2}{|c|}{0.165} & & \\
\hline \multirow{5}{*}{$\begin{array}{l}\text { Surface area } \\
\left(\mathrm{mm}^{2}\right)\end{array}$} & Pre-operative & 5229 & 910.9 & 6801.1 & 1312.1 & 0.149 & Partial Eta Squared $=0.313$ \\
\hline & Post-operative & 5933.5 & 1312.1 & 6221.1 & 1755.5 & 0.798 & Partial Eta Squared $=0.012$ \\
\hline & Change $\%$ & 14 & 10.6 & -8.7 & 1.3 & $0.036^{*}$ & $d=2.331$ \\
\hline & $P$-value & \multicolumn{2}{|c|}{0.128} & \multicolumn{2}{|c|}{0.303} & & \\
\hline & $\begin{array}{l}\text { Effect size (Partial Eta } \\
\text { Squared) }\end{array}$ & \multicolumn{2}{|c|}{0.342} & \multicolumn{2}{|c|}{0.174} & & \\
\hline \multirow{5}{*}{$\begin{array}{l}\text { Minimal } \\
\text { constricted axial } \\
\text { area } \operatorname{SP}\left(\mathbf{m m}^{2}\right)\end{array}$} & Pre-operative & 192.3 & 69.7 & 556.1 & 109.2 & $0.035^{*}$ & Partial Eta Squared $=0.551$ \\
\hline & Post-operative & 344.6 & 83.9 & 497.2 & 116.9 & 0.283 & Partial Eta Squared $=0.188$ \\
\hline & Change $\%$ & 193 & 45.2 & -10.8 & 6.7 & $0.025^{*}$ & $d=2.582$ \\
\hline & $P$-value & \multicolumn{2}{|c|}{$0.007 *$} & \multicolumn{2}{|c|}{0.280} & & \\
\hline & $\begin{array}{l}\text { Effect size } \\
\text { (Partial Eta Squared) }\end{array}$ & \multicolumn{2}{|c|}{0.724} & \multicolumn{2}{|c|}{0.19} & & \\
\hline \multirow{5}{*}{$\begin{array}{l}\text { Minimal } \\
\text { constricted axial } \\
\text { area } \mathrm{T}\left(\mathrm{mm}^{2}\right)\end{array}$} & Pre-operative & 281.6 & 61.1 & 467.9 & 104.6 & 0.392 & Partial Eta Squared $=0.124$ \\
\hline & Post-operative & 444.2 & 115.9 & 427.3 & 142.2 & 0.921 & Partial Eta Squared $=0.002$ \\
\hline & Change $\%$ & 122.4 & 23.4 & 4.2 & 2.1 & $0.010 *$ & $d=2.791$ \\
\hline & $P$-value & \multicolumn{2}{|c|}{$0.014^{*}$} & \multicolumn{2}{|c|}{0.533} & & \\
\hline & $\begin{array}{l}\text { Effect size } \\
\text { (Partial Eta Squared) }\end{array}$ & \multicolumn{2}{|c|}{0.661} & \multicolumn{2}{|c|}{0.068} & & \\
\hline
\end{tabular}

\footnotetext{
*: Significant at $P \leq 0.05$
} 
TABLE(3) Descriptive statistics, results of repeated measures ANOVA test for comparison between linear measurements in the two groups, changes within each group and Mann-Whitney $U$ test for comparison between percentage changes in the two groups

\begin{tabular}{|c|c|c|c|c|c|c|c|}
\hline \multirow{2}{*}{$\begin{array}{l}\text { Linear } \\
\text { measurements } \\
(\mathbf{m m})\end{array}$} & \multirow{2}{*}{ Time } & \multicolumn{2}{|c|}{$\begin{array}{c}\text { Group A } \\
(\mathrm{n}=15)\end{array}$} & \multicolumn{2}{|c|}{$\begin{array}{c}\text { Group B } \\
(\mathrm{n}=15)\end{array}$} & \multirow{2}{*}{$P$-value } & \multirow{2}{*}{ Effect size } \\
\hline & & Mean & SD & Mean & $\mathrm{SD}$ & & \\
\hline \multirow{5}{*}{$\begin{array}{l}\text { Hyoid-Genial } \\
\text { tubercles }\end{array}$} & Pre-operative & 28.3 & 2.7 & 39.3 & 7.2 & $0.019 *$ & Partial Eta Squared $=0.629$ \\
\hline & Post-operative & 37.9 & 3.6 & 38.3 & 7.3 & 0.915 & Partial Eta Squared $=0.002$ \\
\hline & Change $\%$ & 34 & 12.6 & -2.5 & 1.3 & $0.025 *$ & $d=2.582$ \\
\hline & $P$-value & \multicolumn{2}{|c|}{$<0.001 *$} & \multicolumn{2}{|c|}{0.561} & & \\
\hline & $\begin{array}{l}\text { Effect size } \\
\text { (Partial Eta Squared) }\end{array}$ & \multicolumn{2}{|c|}{0.911} & \multicolumn{2}{|c|}{0.059} & & \\
\hline \multirow{5}{*}{$\begin{array}{l}\text { Lateral dimension } \\
(\min \text { SP) }\end{array}$} & Pre-operative & 17.8 & 3.9 & 25 & 6.8 & 0.099 & Partial Eta Squared $=0.388$ \\
\hline & Post-operative & 22.1 & 4.3 & 23.3 & 5.3 & 0.732 & Partial Eta Squared $=0.021$ \\
\hline & Change $\%$ & 24.9 & 7.9 & -6 & 3.7 & $0.025 *$ & $d=2.582$ \\
\hline & $P$-value & \multicolumn{2}{|c|}{$0.001 *$} & \multicolumn{2}{|c|}{0.106} & & \\
\hline & $\begin{array}{l}\text { Effect size } \\
\text { (Partial Eta Squared) }\end{array}$ & \multicolumn{2}{|c|}{0.866} & \multicolumn{2}{|c|}{0.376} & & \\
\hline \multirow{5}{*}{$\begin{array}{l}\text { A-P dimension } \\
(\min \mathrm{SP})\end{array}$} & Pre-operative & 5.7 & 1.3 & 12 & 2.3 & 0.106 & Partial Eta Squared $=0.376$ \\
\hline & Post-operative & 8.9 & 1.6 & 11.9 & 3 & 0.471 & Partial Eta Squared $=0.090$ \\
\hline & Change $\%$ & 58.3 & 20.3 & -1.8 & 2.1 & $0.025^{*}$ & $d=2.582$ \\
\hline & $P$-value & \multicolumn{2}{|c|}{$0.001^{*}$} & \multicolumn{2}{|c|}{0.873} & & \\
\hline & $\begin{array}{l}\text { Effect size } \\
\text { (Partial Eta Squared) }\end{array}$ & \multicolumn{2}{|c|}{0.849} & \multicolumn{2}{|c|}{0.005} & & \\
\hline \multirow{5}{*}{$\begin{array}{l}\text { Lateral dimension } \\
(\min \mathrm{T})\end{array}$} & Pre-operative & 20 & 4.7 & 23.8 & 6.8 & 0.499 & Partial Eta Squared $=0.079$ \\
\hline & Post-operative & 23.9 & 4.8 & 25.5 & 4 & 0.654 & Partial Eta Squared $=0.036$ \\
\hline & Change $\%$ & 28 & 15.9 & 10.3 & 9.5 & 0.456 & $d=0.546$ \\
\hline & $P$-value & \multicolumn{2}{|c|}{0.099} & \multicolumn{2}{|c|}{0.541} & & \\
\hline & $\begin{array}{l}\text { Effect size } \\
\text { (Partial Eta Squared) }\end{array}$ & \multicolumn{2}{|c|}{0.387} & \multicolumn{2}{|c|}{0.065} & & \\
\hline \multirow{5}{*}{$\begin{array}{l}\text { A-P dimension } \\
(\min \mathbf{T})\end{array}$} & Pre-operative & 7.2 & 1.5 & 14.4 & 4.7 & 0.150 & Partial Eta Squared $=0.312$ \\
\hline & Post-operative & 10.5 & 3 & 12.2 & 4.7 & 0.628 & Partial Eta Squared $=0.042$ \\
\hline & Change \% & 52.5 & 14.1 & -11.8 & 10.4 & 0.053 & $d=1.881$ \\
\hline & $P$-value & \multicolumn{2}{|c|}{$0.032 *$} & \multicolumn{2}{|c|}{0.211} & & \\
\hline & $\begin{array}{l}\text { Effect size } \\
\text { (Partial Eta Squared) }\end{array}$ & \multicolumn{2}{|c|}{0.564} & \multicolumn{2}{|c|}{0.246} & & \\
\hline
\end{tabular}




\section{DISCUSSION}

Surgical alteration in the position of the bony facial skeleton will eventually influence the soft tissue relationships as it will influence position and tension in the attached soft tissues secondarily. Such new soft tissue relationships contribute to significant changes in the facial aesthetics and in the airway dimensions. ${ }^{(18-24)}$ Accordingly, this retrospective study was designed to evaluate the volumetric, cross sectional surface area, and linear changes of the airway by using $3 \mathrm{D}$ cone beam computer tomography (CBCT) imaging after two different orthognathic surgeries in the Egyptian population.

Maxillary advancement, through Le-Fort I osteotomy, with an average $5.5 \mathrm{~mm}$ (range of 3-7 mm) was performed for both group in our study and this was in accordance Chang et al ${ }^{(17)}$ Santagata et al ${ }^{(18)}$ Gokce et al $^{(19)}$ who found that the maxillary advancement lead to anterior movement of the soft palate with subsequent increase in volume of the airway. Chang et $^{\boldsymbol{a l}^{(17)}}{ }^{(17}$ found that maxillary advancement of $7 \mathrm{~mm}$ might be adequate to increase the volume of the airway especially nasopharyngeal airway, while more than $7 \mathrm{~mm}$ maxillary advancement will cause a decrease in airway volume "Plateau effect". He noted that patients who underwent maxillary/ mandibular advancement, the oropharynx showed increase in the volume and attributed this to the difference in the adjacent skeletal and soft tissue structures in relation to nasopharyngeal airway and the Oropharyngeal airway, as nasopharyngeal airway surround by a larger proportion of skeletal tissue, whereas the Oropharyngeal airway surround by a larger proportion of soft tissue. Also, the differences in the muscle quality and composition of the pharyngeal walls in each region are unclear. So, the response of each part of the pharyngeal regions to skeletal advancement is different.

Recently, as the airway is a three-dimensional space surrounded by soft tissues so, 3D imaging was necessary for accurate assessment and evaluation of the airway changes after orthognathic surgeries.
In our study 3-D CBCT were used for evaluate the changes of the airway in agreement with the previous authors $(15,19-21)$ who utilized CBCT to evaluate the airway volumetric and dimensional changes. They found that $\mathrm{CBCT}$ imaging technique provided more accurate measurements with lower radiation dose and lower cost than those of other techniques. Conversely, Shaw et al ${ }^{(22)}$ found that two-dimensional measurements from conventional cephalometric lateral skull radiographs were comparable to those from CBCT images.

All volumetric and dimensional changes included in this study airway were performed on oropharynx (OP) space which defined by two planes a superior plane and an inferior plane. Kim et al ${ }^{(21)}$ found that the changes in airway following orthognathic surgery may be inconsistent among reports because the measurements (linear, planar, and volumetric) differ depending on the definition of the airway.

Regarding the statistical evaluation of the airway volume, the mean of OPV was statistically significant postoperatively for patients in group $\boldsymbol{A}$ underwent maxillary and mandibular advancement. The significant higher mean percentage increased by $(46.3 \%)$. These findings were comparable with those mentioned by previous authors. ${ }^{(23-25)}$ Abramson et al ${ }^{(23)}$ found significant increases in lateral and anteroposterior airway diameters, volume, surface area, and cross-sectional areas at multiple sites following maxillary mandibular advancement with genial tubercle advancement. Parsi et al (24) and Hernández-Alfaro et al ${ }^{(25)}$ found significantly increase in Oropharyngeal volume with an average percentage change $(66.39 \%),(69.8 \%)$ respectively after bimaxillary advancement surgery. Chang et $\boldsymbol{a l}{ }^{(17)}$ also found increase in Oropharyngeal airway volume after single mandibular advancement by $(23.5 \%)$ after 6 months post operatively. Conversely, other previous studies that reported either decreased ${ }^{(2,20,21,26)}$ or remains unchanged ${ }^{(27-30)}$ in the volume of total pharyngeal airway following orthognathic surgery. 
However, in group $\boldsymbol{B}$ who underwent maxillary advancement and mandibular setback OPV change was non-significant and showed an average volumetric decrease of $8.7 \%$. The findings of the previous studies, which evaluate airway changes after mandibular setback surgeries, have so far remained controversial. Our volumetric decrease was in agreement with Chang et al ${ }^{(17)}$ who found that there was a slight decrease in the Oropharyngeal airway volume by $5.73 \%$ (range, -3.47 to $12.13 \%$ ) 6 months postoperative after mandibular setback surgery. Park et al. (12) who found volumetric decreased of the oropharynx from $10.92 \pm 3.15$ $\times 10^{3} \mathrm{~mm}^{3}$ to $9.40 \pm 3.09 \times 10^{3} \mathrm{~mm}^{3}$ after mandibular setback surgery for correction of mandibular prognathism with no statistical significant, also $\mathrm{He}$ et $\boldsymbol{a l}^{(31)}$ also found that Oropharyngeal volume and total air way volume decreased either in single or double jaw surgeries with no significant change in nasopharyngeal or oropharyngeal. Other studies had found that the decrease in the oropharynx volume was significant. ${ }^{(2,26,32-34)}$

While our results were in consistent with Vaezi et $a^{(35)}$ who reported that total and oropharyngeal volumes increased and nasopharyngeal and hypopharyngeal volumes decreased after maxillary advancement by Le Fort I osteotomy and mandibular setback, with no significant difference. Havron et al (36) who found that statistically significant increases in airway volume in the group underwent maxillary advancement with mandibular setback. Jokobsone et al. ${ }^{(6)}$ also reported increase CT volumetric measurements in the Oropharyngeal and hypopharyngeal with increase in the total volume of the posterior airway space in all patients underwent to maxillary advancement and mandibular Setback for correction of Class III malocclusion, but the increase was not statistically significant.

In the current study, our results showed decrease in surface area post-operatively in both groups with no statistically significant difference was observed. This was in agreement with $\boldsymbol{H e}$ et $\boldsymbol{a l}^{(31)}$ and $\boldsymbol{H}$ sieh

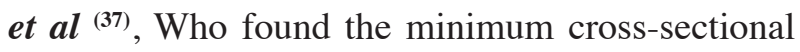

area of the upper airway was narrower 6 months after bimaxillary surgery, while in consistent with Havron et al (36) who found that statistically significant increases in the axial areas at both $\mathrm{C} 1$ (retropalatal region) and $\mathrm{C} 2$ (retroglossal region) in the group underwent mandibular setback with maxillary advancement.

In the present study, statistically significant alterations could be demonstrated with liner measurements evaluation. Our result of linear distance from the hyoid to the genial tubercles showed statistically significantly higher mean \% increase in Hyoid-Genial tubercles measurement in group $\mathbf{A}$ than group B. The results of group A where expected as both maxillary and mandibular advancement will significantly increase the airway volume as the Maxillomandibular advancement (MMA) is an effective treatment for obstructive sleep apnea patients with high success rate. ${ }^{(38,39)}$ also Lin et al ${ }^{(40)}$ evaluated the affects of maxillomandibular complex rotation on the airway volume, he found the hyoid bone was advanced and elevated after segmental maxillomandibular rotational advancement for Far East Asian patients.

Regarding to lateral and antero-posterior measurements, Group A showed a statistically significant increase in mean lateral dimension and A-P dimension at soft palate ( $\mathrm{min}$ SP) and tongue ( $\mathrm{min}$ T) measurements post-operatively this was in accordance with Hsieh et al $^{(37)}$, found enlarges the upper airway and surrounding structures in the anteroposterior and lateral dimensions, as well as raises the hyoid maxillomandibular advancement on the upper airway in patients with obstructive sleep apnea. Also Fairburn et al ${ }^{(41)}$ showed enlargement of lateral and anteroposterior diameters for all patients who underwent maxillary mandibular advancement at all levels. While group B fail to show statistically significant changes at any level. .

The variations and contradictory findings in the literatures investigating changes in airways 
following orthognathic surgeries ${ }^{(\mathbf{1 2}, 28-40)}$ may be attributed to many factors as the complexity of the airway and it's response after different surgeries, differences imaging modalities ${ }^{(2,3,5-7,10)}$ in addition to pharyngeal airway segmentation limits (20-21) and follow-up time ${ }^{(42)}$.Each study, including the present one, used unique amount movements and positioning of the maxilla and mandible besides simple anterior or posterior repositioning, Superior movements or rotations. All these asymmetric changes make uniform evaluation impossible, and all these factors lead to different results obtained.

Several issues need to be taken in to consideration during the interpretation of the data as larger numbers of the patient would be needed to strengthen statistical findings, scheduling of post-operative imaging required, multiple post-operative images would allow the investigator to observe improvements over time. In addition ,the post-operative edema, and soft tissue compensation for new bony positions should be put into consideration as they played an important role in changing the airway dimensions and this was previously reported by Sears et al. $^{(43)}$ and Becker et al..$^{(44)}$ Finally, the dynamic nature of the pharyngeal airway makes evaluation difficult.

Our data are obtained from a static examination. Breathing patterns during image processing were not standardized. We conclude that future research will benefit to a large degree from standardization of imaging recording techniques. These variables are likely to contribute to improvements in estimation and thus analysis of data. Maxillary and mandibular advancement increased the volume of the pharyngeal airways. This increase in volume was higher than the increase in surface area and linear calculation. On the other hand mixed advancement of the maxilla and the mandible setback failed to produce significant changes. This could be seen as a positive result. Further studies with standardized movements, increased patients, set post-operative imaging over a greater period, and uniform imaging acquisition will lead to more comprehensive understanding of airway changes after orthognathic surgery.

\section{CONCLUSIONS}

Significant changes in the measured parameters was observed in patients performing maxillary and mandibular advancement thus increasing the airway volume; which can provide surgeons with a greater confidence that this combination movement is not altering the airway in a negative way. However, patients with mandibular setback surgery showed a non-significant decrease in the airway volume which indicates taking precautions in susceptible patients for obstructive sleep apnea.

\section{REFERENCES}

1. He J, Wang Y, Hu H, Liao Q, Zhang W, Xiang X, Fan X. Impact on the upper airway space of different types of orthognathic surgery for the correction of skeletal class III malocclusion: A systematic review and meta-analysis. Int J Surg. 2017; 38:31-40.

2. Hong JS, Park YH, Kim YJ, Hong SM, Oh KM. Three-dimensional changes in pharyngeal airway in skeletal class III patients undergoing orthognathic surgery. J Oral Maxillofac Surg. 2011; 69:401-408.

3. Abramson Z, Susarla S, August M, Troulis M, Kaban L. Three-dimensional computed tomographic analysis of airway anatomy in patients with obstructive sleep apnea. J Oral Maxillofac Surg. 2010; 68: 354-362.

4. Moscarino S, Kötter F, Brandt M, Modabber A, Kniha K, Hölzle F, Wolf M, Möhlhenrich SC. Influence of different surgical concepts for moderate skeletal class II and III treatment on the nasopharyngeal airway space. J Craniomaxillofac Surg. 2019; 47: 1489-1497.

5. Susarla SM, Abramson ZR, Dodson TB, Kaban LB. Cephalometric measurement of upper airway length correlates with the presence and severity of obstructive sleep apnea. J Oral Maxillofac Surg. 2010; 68:2846-2855.

6. Jakobsone G, Neimane L, Krumina G. Two and three dimensional evaluation of the upper airway after bimaxillary correction of Class III malocclusion. Oral Surg Oral Med Oral Pathol Oral Radiol Endod. 2010; 110:234-242. 
7. Kuo GP, Torok CM, Aygun N, Zinreich SJ. Diagnostic imaging of the upper airway. Proc Am Thorac Soc. 2011; 8:40-5.

8. Lenza MG, Lenza MM, Dalstra M, Melsen B, Cattaneo PM. An analysis of different approaches to the assessment of upper airway morphology: a CBCT study. Orthod Craniofac Res. 2010;13: 96-105.

9. Weissheimer A, Menezes LM, Sameshima GT, Enciso R, Pham J, Grauer D. Imaging software accuracy for 3-dimensional analysis of the upper airway. Am J Orthod Dentofacial Orthop. 2012;142:801-13

10. Carter JB, Stone JD, Clark RS, Mercer JE. Applications of Cone-Beam Computed Tomography in Oral and Maxillofacial Surgery: An Overview of Published Indications and Clinical Usage in United States Academic Centers and Oral and Maxillofacial Surgery Practices. J Oral Maxillofac Surg. 2016; 74: 668-679.

11. Yeung AWK, Jacobs R, Bornstein MM. Novel low-dose protocols using cone beam computed tomography in dental medicine: a review focusing on indications, limitations, and future possibilities. Clin Oral Investig. 2019; 23: 2573-2581.

12. Park JW, Kim NK, Kim JW, Kim MJ, Chang YI: Volumetric, planar, and linear analyses of pharyngeal airway change on computed tomography and cephalometry after mandibular setback surgery. Am J Orthod Dentofacial Orthop. 2010; 138:292-299.

13. Burkhard JP, Dietrich AD, Jacobsen C, Roos M, Lübbers HT, Obwegeser JA. Cephalometric and three-dimensional assessment of the posterior airway space and imaging software reliability analysis before and after orthognathic surgery. J Craniomaxillofac Surg. 2014; 42:1428-1436.

14. Parsi GK, Alsulaiman AA, Kotak B, Mehra P, Will LA, Motro M. Volumetric changes the upper airway following maxillary and mandibular advancement using cone beam computed tomography. Int J Oral Maxillofac Surg. 2019; 48: 203-210of

15. Alcalde LFA, Faria PEP, Nogueira RLM, Chihara L, Sant'Ana E. Computed tomography visualizing alterations in the upper airway after orthognathic surgery. J Craniomaxillofac Surg. 2019;47:1041-1045

16. .Valladares-Neto J, Silva MA, Bumann A, Paiva JB, RinoNeto J. Effects of mandibular advancement surgery combined with minimal maxillary displacement on the volume and most restricted cross-sectional area of the pharyngeal airway. Int J Oral Maxillofac Surg. 2013; 42: 1437-1445.
17. Chang MK, Sears C, Huang JC, Miller AJ, Kushner HW, Lee JS. Correlation of Airway volume with orthognathic surgical movement using Cone-Beam Computed Tomography. J Oral Maxillofac Surg. 2015; 73: 67-76.

18. Santagata M, Tozzi U, Lamart E, Tartaro G. Effect of Orthognathic Surgery on the Posterior Airway Space in Patients Affected by Skeletal Class III Malocclusion. J Maxillofac Oral Surg. 2015;14: 682-686.

19. Gokce SM, Gorgulu S, Gokce HS, Bengi AO, Karacayli U, Ors F. Evaluation of pharyngeal airway space changes after bimaxillary orthognathic surgery with a 3-dimensional simulation and modeling program. Am J Orthod Dentofacial Orthop 2014; 146:477-492.

20. Brunetto DP, Velasco L, Koerich L, Araujo MT: Prediction of 3-dimensional pharyngeal airway changes after orthognathic surgery: a preliminary study. Am J Orthod Dentofacial Orthop 2014; 146:299-309.

21. Kim HS, Kim GT, Kim S, Lee JW, Kim EC, Kwon YD: Three-dimensional evaluation of the pharyngeal airway using cone-beam computed tomography following bimaxillary orthognathic surgery in skeletal class III patients. Clin Oral Investig 2016; 20:915-922.

22. Shaw K, McIntyre G, Mossey P, Menhinick A, Thomson D: Validation of conventional 2D lateral cephalometry using 3D cone beam CT. J Orthod. 2013; 40:22-8.

23. Abramson Z, Susarla SM, Lawler M, et al. Three-dimensional computed tomographic airway analysis of patients with obstructive sleep apnea treated by maxillomandibular advancement. J Oral Maxillofac Surg 2011; 69:677-86.

24. Parsi GK, Alsulaiman AA, Kotak B, Mehra P, Will LA, Motro M. Volumetric changes of the upper airway following maxillary and mandibular advancement using cone beam computed tomography. Int J Oral Maxillofac Surg. 2019 Feb; 48(2):203-210.

25. Hernández-Alfaro F, Guijarro-Martínez R, MarequeBueno J. Effect of mono- and bimaxillary advancement on pharyngeal airway volume: cone-beam computed tomography evaluation. J Oral Maxillofac Surg. 2011 Nov; 69(11):e395-400

26. Li YM, Liu JL, Zhao JL, Dai J, Wang L, Chen JW: Morphological changes in the pharyngeal airway of female skeletal class III patients following bimaxillary surgery: a cone beam computed tomography evaluation. Int J Oral Maxillofac Surg 2014; 43:862-867.

27. Shin JH, Kim MA, Park IY, Park YH: A 2-year followup of changes after bimaxillary surgery in patients with 
mandibular prognathism: 3-dimensional analysis of pharyngeal airway volume and hyoid bone position. J Oral Maxillofac Surg 2015; 73:340-349.

28. Hatab NA, Konstantinovic VS, Mudrak JK: Pharyngeal airway changes after mono- and bimaxillary surgery in skeletal class III patients: cone-beam computed tomography evaluation. J Craniomaxillofac Surg 2015; 43:491-496.

29. Hart PS, McIntyre BP, Kadioglu O, Currier GF, Sullivan SM, Li J, Shay C: Postsurgical volumetric airway changes in 2-jaw orthognathic surgery patients. Am J Orthod Dentofacial Orthop 2015; 147:536-546.

30. Uesugi T, Kobayashi T, Hasebe D, Tanaka R, Ike M, Saito $\mathrm{C}$ : Effects of orthognathic surgery on pharyngeal airway and respiratory function during sleep in patients with mandibular prognathism. Int J Oral Maxillofac Surg 2014; 43:1082-1090.

31. He L, He S, Wu X, Huang Y. Three-Dimensional Morphological Changes of the Upper Airway in Patients With Skeletal Class III Malocclusion After Orthognathic Surgery. J Craniofac Surg. 2019;30:2451-2455

32. Lee Y, Chun YS, Kang N, Kim M. Volumetric changes in the upper airway after bimaxillary surgery for skeletal class III malocclusions: a case series study using 3-dimensional cone-beam computed tomography. J Oral Maxillofac Surg. 2012; 70: 2867-2875.

33. Kim MA, Kim BR, Choi JY, Youn JK, Kim YJ, Park YH. Three-dimensional changes of the hyoid bone and airway volumes related to its relationship with horizontal anatomic planes after bimaxillary surgery in skeletal Class III patients. Angle Orthod. 2013;83: 623-9.

34. Kim MA, Park YH. Does upper premolar extraction affect the changes of pharyngeal airway volume after bimaxillary surgery in skeletal class III patients? J Oral Maxillofac Surg. 2014; 72:165.e1-10.

35. Vaezi T, Zarch SHH, Eshghpour M, Kermani H. Twodimensional and volumetric airway changes after bimaxillary surgery for class III malocclusion. J Korean Assoc Oral Maxillofac Surg. 2017; 43: 88-93.
36. Havron AG, Aronovich S, Shelgikar AV, Kim HL, Conley RS. 3D Airway changes using CBCT in patients following mandibular setback surgery \pm maxillary advancement. Orthod Craniofac Res. 2019 May; 22 Suppl 1:30-35.

37. Hsieh YJ, Liao YF. Effects of maxillomandibular advancement on the upper airway and surrounding structures in patients with obstructive sleep apnoea: a systematic review. Br J Oral Maxillofac Surg. 2013 Dec; 51(8):834-40.

38. Li KK, Powell NB, Riley RW, Troell RJ, Guilleminault C. Long-term results of maxillomandibular advancement surgery. Sleep Breath 2000; 4:137-139. 3.

39. Conradt R, Hochban W, Brandenburg U, Heitmann J, Peter JH. Long term results after surgical treatment of obstructive sleep apnea by maxillomandibular advancement. Euro Respir J 1997; 10:123-128.

40. Lin $\mathrm{CH}$, Liao $\mathrm{YF}$, Chen $\mathrm{NH}$, et al. Three-dimensional computed tomography in obstructive sleep apneics treated by maxillomandibular advancement. Laryngoscope 2011;121:1336-47

41. Fairburn SC, Waite PD, Vilos G, et al. Three-dimensional changes in upper airways of patients with obstructive sleep apnea following maxillomandibular advancement. J Oral Maxillofac Surg 2007;65:6-12

42. Kim MA, Kim BR, Youn JK, Kim YJ, Park YH. Head posture and pharyngeal airway volume changes after bimaxillary surgery for mandibular prognathism. J Craniomaxillofac Surg. 2014; 42:531-535.

43. Sears CR, Miller AJ, Chang MK, Huang JC, Lee JS. Comparison of pharyngeal airway changes on plain radiography and cone-beam computed tomography after orthognathic surgery. J Oral Maxillofac Surg 2011;69: 385-394.

44. Becker OE, Avelar RL, Göelzer JG, Dolzan Ado N, Haas OL Jr, De Oliveira RB: Pharyngeal airway changes in Class III patients treated with double jaw orthognathic surgery--maxillary advancement and mandibular setback. J Oral Maxillofac Surg. 2012; 70: 639-647. 